\title{
Anemia and Low Testosterone Associated with Male Type 2 Diabetic Patients.
}

\author{
Samal Hakeem Kareem AL-Jaff* Majid Ahmed Naseif AL-Bayati* \\ Noor Adil Abood** \\ * Department of Biology,College of Science, AL- Mustansireah University. \\ .** Biotechnology ,College of sciences, Al-Mamon University.
}

Accepted - November - 2010

\section{Summary}

Diabetes Type 2 is associated with low testosterone levels in men, The mechanism of which is unclear. Thus the aim of this study was to estimate the incidence of low testosterone in T2D patients men/ and with aging, and the possibility of anemia in these patients and the anemia accompanied the T2D cases is due to T2D itself or by the effect of low testosterone. Present work was studied two male groups with different age first, group A age (31-40) years, 60 person \{30control \& 30 T2D patients $\}$ ( 3 persons for each age), second, group B age (41-50) years ,60 person , $\{30$ control \& 30 patients ( 3 persons for each age). Blood was taken from these groups and sugar, $\mathrm{PCV}, \mathrm{Hb}$ and Testosterone levels were measured comparing with control of each and between two groups and in each data, the mean data of the same age has been taken. Present results showes that male T2D patients have significantly low T. levels $\mathrm{P} \leq 0.05$ and significantly $\mathrm{P} \leq 0.05$ low $\mathrm{Hb}$ and $\mathrm{PCV}$ comparing with sugar level which was significantly high $\mathrm{P} \leq 0.05$, and group $\mathrm{B}$ (41-50) age have the lowest $\mathrm{T}$. level ,PCV and $\mathrm{Hb}$ with higher sugar levels. We concluded that anemia and low $\mathrm{T}$. level associated with T2D, and the effect of low testosterone on anemia is little .Our data shows that low $\mathrm{T}$. level and anemia increased with age T2D groups in both group $\mathrm{A} \& \mathrm{~B}$, and in control groups in both $\mathrm{A} \& \mathrm{~B}$ bout it is more sever and alarming in $\mathrm{T} 2 \mathrm{D}$ cases.

Key words: Anemia, low testosterone, diabetestype2, diabetic patients.

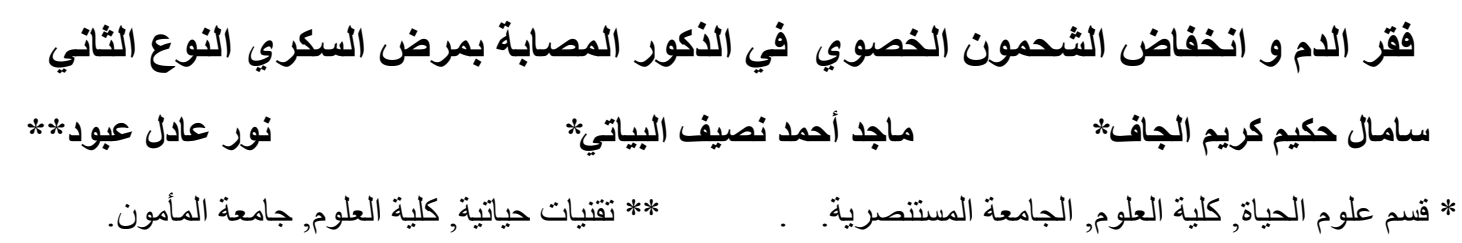

الخلاصة

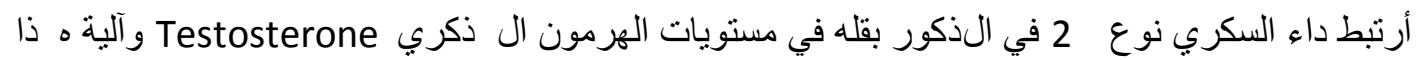

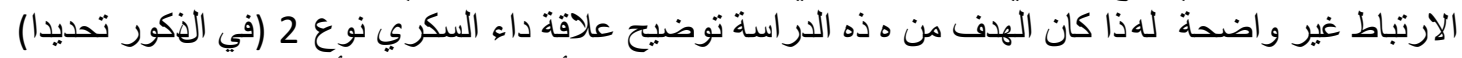

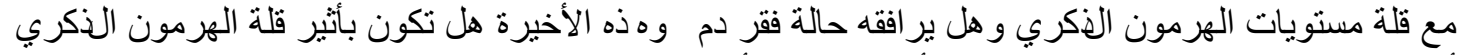

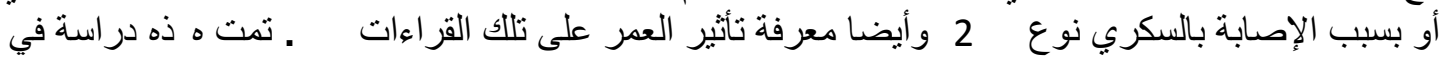

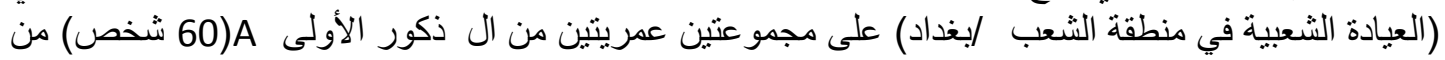

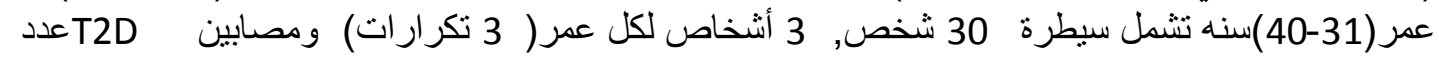

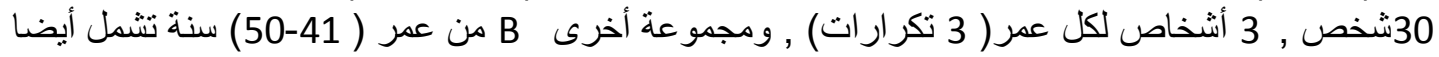

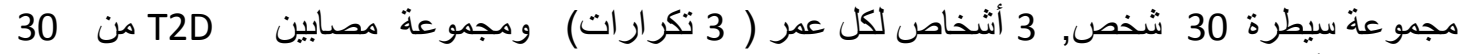

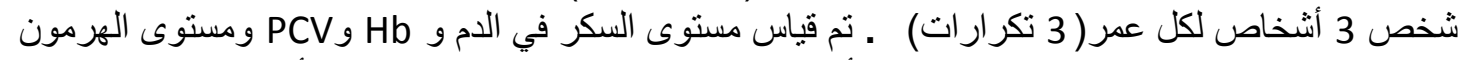

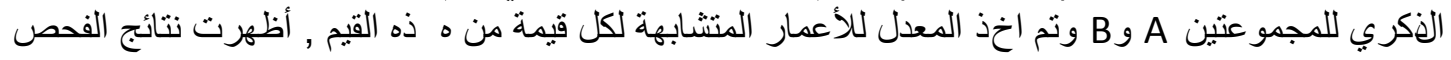




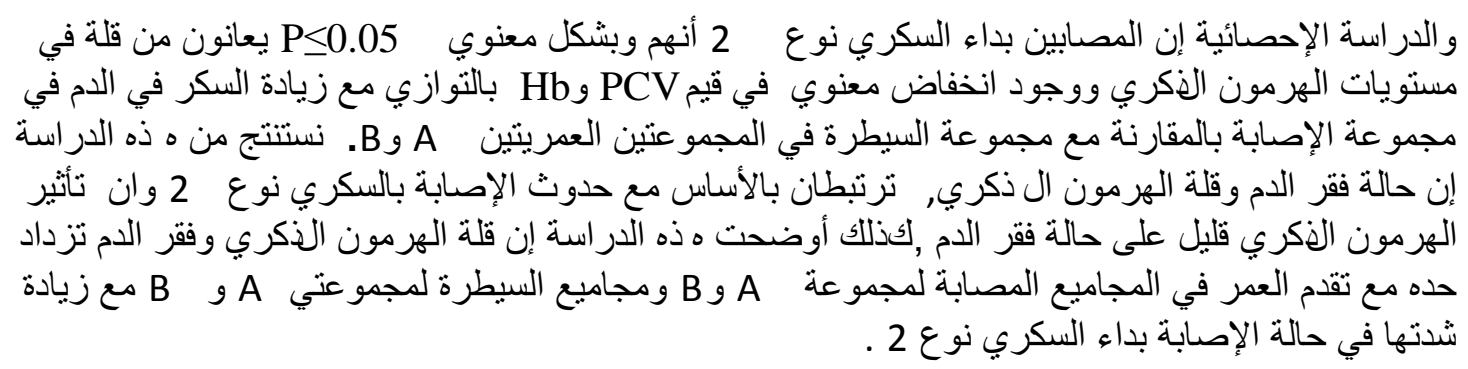

\section{Introduction}

In diabetes diseases \{about $90-95 \%$ of all cases individuals with Type 2 Diabetes (T2D) do manufacture insulin. Sometime even more than necessary .However their reject and/or do not detect it, resulting in that the body perceived an a deficiency. The onset of this type of diabetes usually accured after age 30 , this likelihood of onset increases with age, about $15 \%$ of people over 70 have T2D.(1). Studies linking low Testosterone (T.) level to T2D have been around but they haven't received much attention because both $\mathrm{T} 2 \mathrm{D}$ and low $\mathrm{T}$. levels are associated with aging but some studies have shown that levels are lower in T2D men than non-diabetic in the same age. (2). Other studies mentioned that T. deficiency is common in men with diabetes regardless of the type and $\mathrm{T}$. level are partly influenced by insulin resistance (IR).(3). Testosterone levels are partly influenced by Insulin Resistance (IR) \{problem in target cell, Hyporesponsiveness to insulin, after that combined to cause T2D (4) $\}$ which may represent an important avenue for intervention. The sign and symptoms of low T. may include diminished interest in sex , erectile dysfunction, increased fat mass, depressed mood and fatigue. Men with chronic condition such as diabetes, obesity, hypertension, hyperlipidemia and asthma are more likely to have low T. compared to other men(5). Accordingto(6,7\&8) mentioned that males with T2D have low T. concentration and those are likely to develop T2D. While (2) demonstrated that one third of males with T2D had subnormal T. level and that most of these patients had total and free T. level in low normal and subnormal range and it associated with Sex Hormone Binding Globulin (SHBG) concentration in the low normal range .this study also demonstrated that these patient had low LH \& FSH concentration thus these patients had Hypogonadotrophic Hypogonadism (H.H.)(2)\{circulating Gonadotropin levels are depressed (9)\}. The first study to investigate the occurrence of (H.H.) in younger patient with T2D mentioned that patients between the age of $18-35$ years were shown to have (H.H.) at rate of 58\%.(10). The presence of H.H. (depressed Gonadotropin) in T2D patients at such a high rate is alarming because such patients are in the prime reproductive years and likely not only to suffer from features of low $\mathrm{T}$. concentration but also potentially from impaired spermatogenesis. (11). The aims of this work was to study the level of T. and sugar level in T2D patients men between 30-40 years and 41-50 years old and to investigate the incidence of anemia in these patients which is either caused by T2D itself or by the effect of low T. level.

\section{Material and Methods}

This study was established in/and with the help of \{The Public Clinic in Al- Shaab /Baghdad \},120 male person were studied and had been divided to two groups. 
Iraqi J. Vet. Med. 34 ( 2 ): $58-65$; ( 2010 ).

1-Group A :- Contain 60 person aged from 31 to 40 years old \{30 normal, 3 person in each same age \& 30 person T2D previously diagnosed, 3 person in the same age .

2-Group B :- Contain 60 person aged from 41 to 50 years old $\{30$ normal ,3 persons in the same age \& 30 person T2D previously diagnosed , 3 persons in the same age .

Two samples were collected from each person in both groups and titled (all in fasting state) .One: A whole blood for measuring Hb \&PCV immediately, according to the procedure in their kits.

a- PCV Test : Hole blood using capillary tubes (red), were centrifuged by using microhematocite centrifuge and being readed by its special PCV ruler.

b- $\mathrm{Hb}$ Test : Tested by using Drabkin's solution $0.02 \mathrm{ml}$ of blood with $5 \mathrm{ml}$ of Drabkin's solution and leaved for 5 minutes, Then it measured by using spectrophotometer on wave length $(546 \mathrm{~mm})$ according to the kit.

The other half was used to get serum for total testosterone levels in blood \& for blood sugar .Then it kept in deep freeze to be measured later.

a- Testosterone levels : Measured in/by the help of (Analytical Central Lab./Mainstay of Health) by ELIZA using kit by \{EORIMMUNE\} ${ }^{\circledR}$ AG. Germany.

b- Sugar Test: $1 \mathrm{ml}$ of glucose solution with 10 microgram Patient's serum and being left for $5 \mathrm{~min}$ in room temperature then tested by spectrophotometer on 550 wave length, according to the kit that produced by (BIOMAGRIB)®

\section{Statistical Analysis:}

T. Test was emplaced to study the significance of differences between data in the present work by Least Significant Differences (LSD) $\mathrm{P} \leq 0.05$ using (SAS 2001) program.(12)

\section{Results}

In group A table $\{1$ and diagram 1$\}$ the data showed a significant increase in sugar levels in group A (T2D) comparing with group A (control) $\mathrm{P} \leq 0.05$, and there were a significant decrease $\mathrm{P} \leq 0.05$ in $\mathrm{Hb}, \mathrm{PCV}$ and $\mathrm{T}$. levels in group $\mathrm{A}$ (T2D) comparing with A control. The same as in group B: \{table 2 and diagram 2\} sugar are significantly higher $\mathrm{P} \leq 0.05$ in group $\mathrm{B}$ (T2D)comparing with $\mathrm{B}$ (control) , and $\mathrm{Hb}$, $\mathrm{PCV}$ and T. levels are lower significantly $\mathrm{P} \leq 0.05$ in group $\mathrm{B}(\mathrm{T} 2 \mathrm{D})$ than in group $\mathrm{B}$ (control). These data showed also differences in means between group A (T2D) \& group B (T2D): sugar is higher in group B (T2D) than in A (T2D) and $\mathrm{Hb}, \mathrm{PCV}$ and T. levels in group B (T2D) lower than group A (T2D) . 
Table (1):Group A: age $\{31-40\}$ years: Sugar , PCV, Hb \& Testosterone level in both (control and T2D) *.

\begin{tabular}{|c|c|c|c|c|c|c|c|c|}
\hline \multirow[t]{2}{*}{ Age } & \multicolumn{2}{|c|}{ Sugar. $\mathrm{mg} / \mathrm{dl}$} & \multicolumn{2}{|c|}{ Hb. $\mathrm{mg} / \mathrm{dl}$} & \multicolumn{2}{|c|}{ PCV. \% } & \multicolumn{2}{|c|}{ Testosterone. $\mu \mathrm{g} / \mathrm{ml}$} \\
\hline & Control & T2D & control & T2D & control & T2D & Control & T2D \\
\hline 31 & 180 & 321 & 185 & 125 & 47 & 35 & 4.3 & 2.0 \\
\hline 32 & 170 & 243 & 120 & 145 & 38 & 37 & 5.0 & 3.0 \\
\hline 33 & 100 & 245 & 173 & 150 & 40 & 42 & 8.0 & 3.0 \\
\hline 34 & 120 & 198 & 170 & 155 & 46 & 39 & 7.0 & 5.1 \\
\hline 35 & 80 & 334 & 135 & 110 & 38 & 40 & 8.2 & 1.5 \\
\hline 36 & 185 & 260 & 170 & 165 & 49 & 41 & 7.2 & 5.2 \\
\hline 37 & 125 & 327 & 130 & 120 & 39 & 38 & 7.2 & 3.4 \\
\hline 38 & 130 & 280 & 140 & 155 & 36 & 43 & 6.7 & 5.1 \\
\hline 39 & 200 & 387 & 180 & 127 & 46 & 39 & 6.0 & 2.5 \\
\hline 40 & 100 & 271 & 150 & 128 & 38 & 33 & 7.4 & 3.7 \\
\hline $\begin{array}{c}\text { Mean } \\
\pm S E\end{array}$ & $\begin{array}{l}139.00 \\
\pm 13.18\end{array}$ & $\begin{array}{l}286.60 \\
\pm 17.51\end{array}$ & $\begin{array}{c}155.30 \\
\pm 7.30\end{array}$ & $\begin{array}{c}132.00 \\
\pm 5.77\end{array}$ & $\begin{array}{l}41.00 \\
\pm 1.48\end{array}$ & $\begin{array}{l}38.70 \\
\pm 1.19\end{array}$ & $\begin{array}{c}6.70 \\
\pm 0.39\end{array}$ & $\begin{array}{r}3.45 \\
\pm 0.41\end{array}$ \\
\hline$* *$ & \multicolumn{2}{|c|}{$A B$} & \multicolumn{2}{|c|}{$A B$} & \multicolumn{2}{|c|}{$A B$} & \multicolumn{2}{|c|}{$A B$} \\
\hline LSD & \multicolumn{2}{|l|}{46.06} & \multicolumn{2}{|c|}{19.55} & \multicolumn{2}{|c|}{3.96} & \multicolumn{2}{|c|}{1.21} \\
\hline
\end{tabular}

*control contain 30 person ( 3 persons for each age) \& T2D contain 30 person (3 persons for each age). **: Means with the different letters are significantly different $P \leq 0.05$, between control and T2D.

Table (2):Group B: age $\{41-50\}$ years: Sugar, PCV, Hb \& Testosterone level in both (control and T2D) *.

\begin{tabular}{|c|c|c|c|c|c|c|c|c|}
\hline \multirow[t]{2}{*}{ Age } & \multicolumn{2}{|c|}{ Sugar. mg/dl } & \multicolumn{2}{|c|}{ Hb. mg/dl } & \multicolumn{2}{|c|}{ PCV. \% } & \multicolumn{2}{|c|}{ Testosterone. $\mu \mathrm{g} / \mathrm{ml}$} \\
\hline & control & T2D & control & T2D & control & T2D & Control & T2D \\
\hline 41 & 95 & 346 & 140 & 130 & 39 & 43 & 5.2 & 1.5 \\
\hline 42 & 210 & 385 & 130 & 102 & 38 & 33 & 4.1 & 2.6 \\
\hline 43 & 100 & 371 & 160 & 150 & 46 & 43 & 7.0 & 2.6 \\
\hline 44 & 210 & 445 & 120 & 125 & 39 & 40 & 3.5 & 2.1 \\
\hline 45 & 120 & 439 & 180 & 115 & 45 & 38 & 7.0 & 1.8 \\
\hline 46 & 170 & 385 & 120 & 116 & 40 & 36 & 4.2 & 2.0 \\
\hline 47 & 110 & 480 & 140 & 120 & 50 & 39 & 6.0 & 2.2 \\
\hline 48 & 180 & 510 & 150 & 130 & 39 & 38 & 4.0 & 1.9 \\
\hline 49 & 195 & 320 & 170 & 130 & 44 & 38 & 6.1 & 2.1 \\
\hline 50 & 200 & 435 & 130 & 115 & 48 & 37 & 3.0 & 2.0 \\
\hline $\begin{array}{c}\text { Mean } \\
\pm S E\end{array}$ & $\begin{array}{r}159.00 \\
\pm 14.99\end{array}$ & $\begin{array}{r}411.60 \\
\pm 19.01\end{array}$ & $\begin{array}{c}144.00 \\
\pm 6.53\end{array}$ & $\begin{array}{c}123.30 \\
\pm 4.09\end{array}$ & $\begin{array}{r}42.80 \\
\pm 1.37\end{array}$ & $\begin{array}{l}38.60 \\
\pm 0.94\end{array}$ & $\begin{array}{c}4.91 \\
\pm 0.51\end{array}$ & $\begin{array}{c}2.08 \\
\pm 0.10\end{array}$ \\
\hline$* *$ & \multicolumn{2}{|c|}{$A B$} & \multicolumn{2}{|c|}{$A B$} & \multicolumn{2}{|c|}{$A B$} & \multicolumn{2}{|c|}{$A B$} \\
\hline LSD & \multicolumn{2}{|c|}{50.87} & \multicolumn{2}{|c|}{16.19} & \multicolumn{2}{|c|}{3.50} & \multicolumn{2}{|c|}{1.10} \\
\hline
\end{tabular}

*control contain 30 person ( 3 persons for each age) \& T2D contain 30 person (3 persons for each age). **: Means with the different letters are significantly different $P \leq 0.05$. , between control and T2D. 
Iraqi J. Vet. Med. 34 ( 2 ): $58-65$; ( 2010 ).

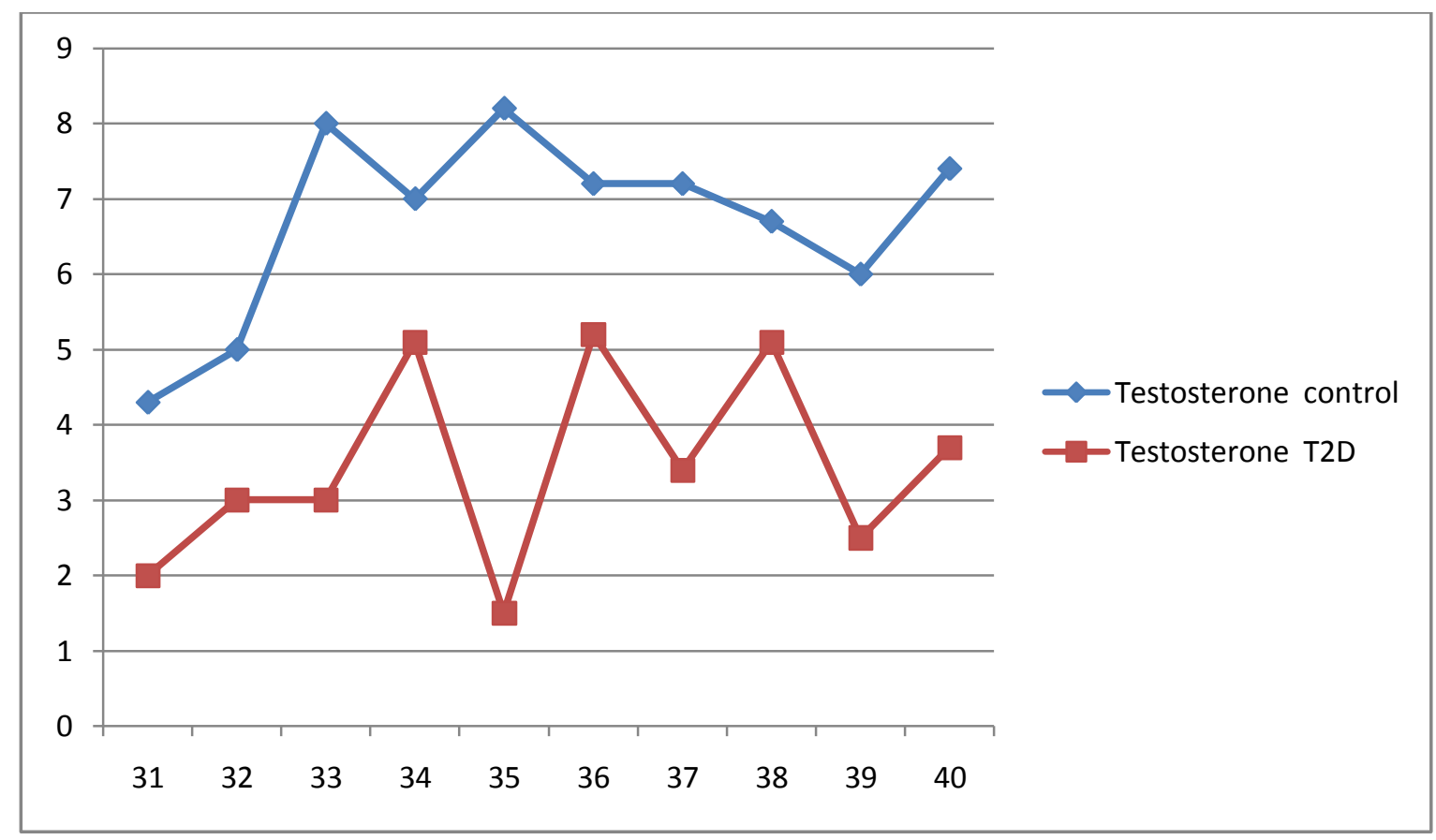

Diagram (1):Testosterone level in Group A:Showing levels of Testosterone with age in control group \{above $\}$ and in T2D group \{under\}.

*Ventricle axon refers to Testosterone levels $(\mu \mathrm{g} / \mathrm{ml}) \&$ Horizontal axon refers to Age (years)

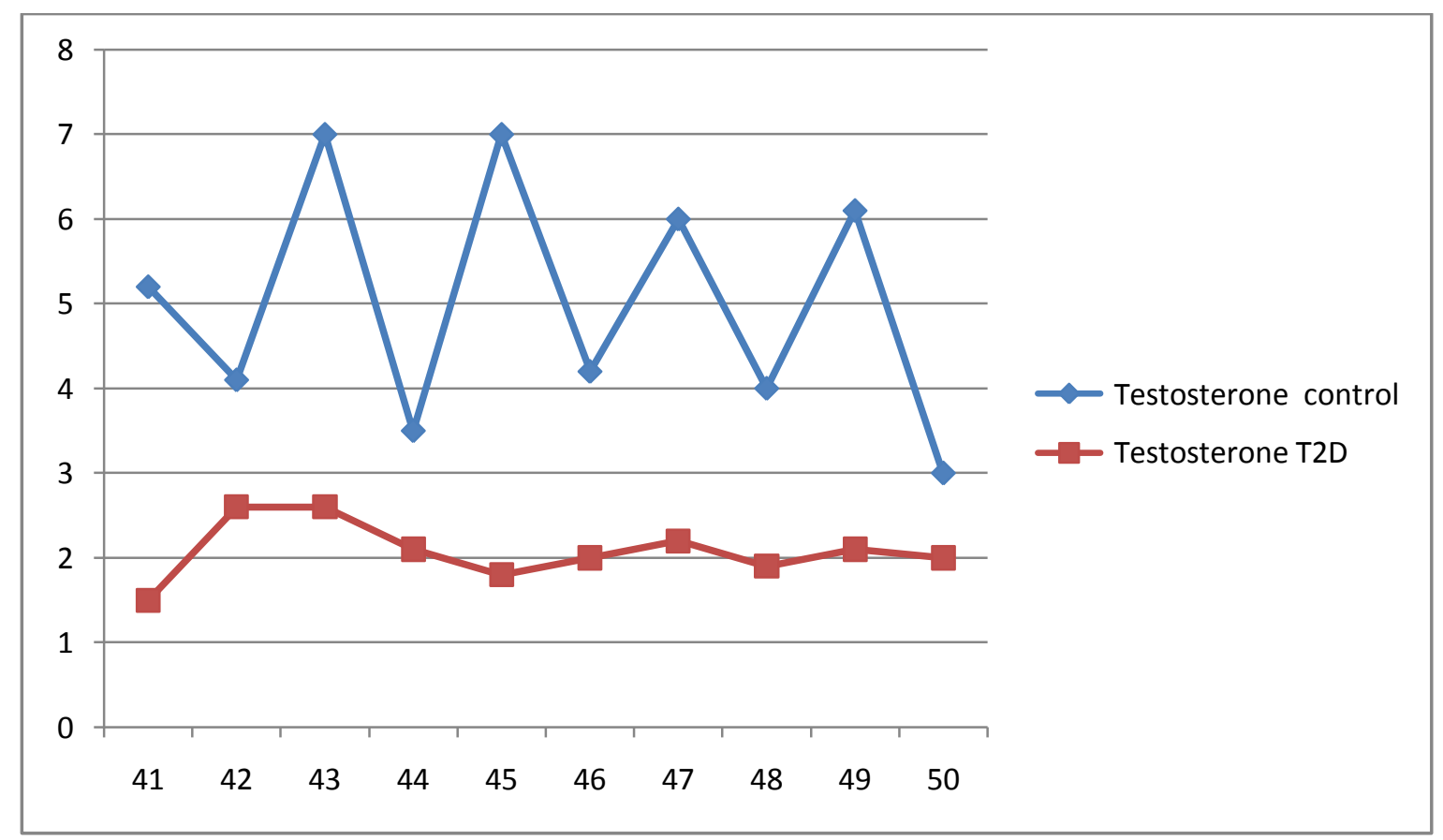

Diagram (2): Testosterone levels in Group B :Showing levels of Testosterone with age in control group $\{$ above $\}$ and in T2D group $\{$ under\}.

*Ventricle axon refers to Testosterone levels $(\mu \mathrm{g} / \mathrm{ml}) \&$ Horizontal axon refers to Age (years) 
Iraqi J. Vet. Med. 34 ( 2 ): $58-65$; ( 2010 ).

\section{Discussion}

Significant decreased of T. level comparing with Significantly sugar increased of sugar that appeared in group A and in group B between control and T2D, this results go's with $(1,2,4 \& 13)$.how noticed that patient with T2D are more likely to have low T. Their evidence linking decreased plasma levels of T. and T2D , and they concluded that androgen deficiency is linked with T2D and IR . A research by (13) on 6426 men suggested that the higher T. level are associated with lower risk of T2D and vice versa, low Sex Hormones Binding Globulin (SHBG) and T., predict higher glucose levels and that is what our data shows. It has been suggested that the Pathophysiological inverse relationship between $\mathrm{T}$. and insulin is associated with both IR and low SHBG levels, if this hypotheses is correct the reduction in T. levels accounted for low levels of SHBG alone $\{\mathrm{T}$. molecule that combined with SHBG and that free $\mathrm{T}$. should be normal but (14) demonstrate a positive relationship between total T. levels and insulin sensitivity \{increase sugar in blood $\}$ in men independent to SHBG ,also in male rats, castration leads to a rapid development of Insulin Resistance which is corrected by physiological T. replacement (15). An alternative explanation for inverse relationship between $\mathrm{T}$. and insulin is that they are directly linked independently of SHBG levels. The available evidence suggested that the relationship between $\mathrm{T}$. and insulin may be bidirectional \{normal insulin normal $\mathrm{T}$. level but IR decrease T. level\}. Insulin signaling in the brain play an important role in regulation reproductive function ,insulin facilitate Gonadotrpin Releasing Hormone $(\mathrm{GnRH})$ release from hypothalamus neurons .(16). Researchers found that Insulin promote $(\mathrm{GnRH})$ secretion in the hypothalamus GnRH neuronal cell line (17). And stimulates Gonadotropin secretion from cultured pituitary cells (18) . Insulin receptors are present on Leydig cells also (19), and insulin stimulate T. production in Leydig cell cultures(19 \&20). In animal studies lowering plasma insulin levels decreases pituitary LH content and plasma LH levels (21), and acute Hyperinsulnemia causes a modest increase in T. level(21). Whereas lowering insulin levels with (Diazoxide) reduced serum T. levels (22), this stimulate effects of insulin on the Hypothalamic Pituitary Gonadal (HPG) axis appears to contradict the inverse relationship between T. and insulin levels noted (23).This could be explained by the decreased sensitivity of HPG axis to insulin resistance states. In one hand There is controversy as to whether it is only free $\mathrm{T}$. that is biologically active or / with total $\mathrm{T}$. giving that $\mathrm{T}$. bound to SHBG combined to cell surface receptors in prostate tissue leading to activation of adenylcyclase and generation of cAMP (24), and on the other hand (14) demonstrated a positive relationship between T. level and insulin sensitivity .For these reasons this woke was depend on total $\mathrm{T}$. levels instead of free $\mathrm{T}$. as the most robust index of androenicity. The differences between group A \& B in sugar levels and T. levels is may be due to aging and the metabolic differences between age 30-40 and age 41-50 .Both T2D and low T. level associated with aging (2). Patients with T2D have Hypogonadotrophic Hypogonadism with high CRD level and they suffering from chronic state of inflammation (25\& 26) .The significant low $\mathrm{Hb}, \mathrm{PCV}$, in group A between control and T2D , and in group B between control and T2D is maybe due to a state of inflammation .Inflammation may affect hematocrit in two ways first: They may suppress Erythropoietin secretion (25) and second: they may cause increased apoptotic death of red cell procuresses resulting in no increase in Erythropoiesis despite elevated Erythropoietin levels (27\&28). These mechanism are relevant to the pathogenesis of anemia of chronic diseases thus anemia in T2D may in part attributable to processes similar to those involved in chronic inflammation 
diseases in addition to the contribution by low $\mathrm{T}$. concentration which appeared in our study. Low $\mathrm{Hb}, \mathrm{PCV}$ in group $\mathrm{B}$ control comparing with group A control may be due to low T. in group B control. Low level of T. hormone are associated with aging. We concluded that the T2D disease affects directly to lowering T. level through HPG axis \{ insulin signal transduction reduce GnRH secretion\} and that a state of inflammation accompanied with chronic T2D cause anemia appeared in T2D patients in both groups.

\section{References}

1. Tsai EC Matsumoto A M Fujimoto W Y and Boyko E J (2004). Association of Bioavailable, Free, and Total Testosterone with Insulin Resistance: Influence of Sex Hormone-Binding Globulin and Body Fat. Diabetes Care: 27:861-868.

2. DhindsaS Prabhakar S Sethi M Bandyopadshyay A Chaudhuri A and Dandona P (2004). Frequent occurrence of Hypogonadotrophic Hypogonadism in Type 2 Diabetes .The J Clin Endo. Metab.89;(11): 5462-5468.

3. Grossmann M Thomas M C Panagiotopoulos S Sherpe K MacIsaac R J Clarke S Zajac JD and Jerumc G (2007).Low Testosterone Levels are Common and Associated With Insulin Resistance in Men With Diabetes . The J Clin Endo Metab.93;(5): 834-1840..

4. Vander A Sherman J and Luciano D (1998). Human Physiology ,The Mechanism of body Function.Seventh Edition .WCB.McGeaw-Hill.pp.605.

5. Chandel A Dhindsa S Topiwala S Chaudhuri A and Dandona P (2008). Testosterone Concentrations in Young Patients with Diabetes Mellitus. Diabetes Care Epub .9346-752- 704

6. Barrett-Connor E Khaw K T Yen S S(1990). Endogenous Sex Hormone Levels in Oldser Adult Men With Diabetes Mellitus. Am J Epidemiol. 132:895901.

7. Barrett-Connor E(1992). Lower Endogenous Androgen Levels and Dyslipidemia in Men With Non-Insulin-Dependent Diabetes Mellitus. Ann Intern Med. 117:807-811.

8. Ganong WF (2003).Review of Medical Physiology .Twenty -first Edition .Lang medical Books / McGraw-Hill. Medical Publishing Division .pp.437 .371 .

9. Andersson B Marin P Lissner L Vermeulen A Bjorntorp P (1994).Testosterone Concentrations in Women and Men With NIDDM. Diabetes Care. 17:405-411.

10. Bhatia V Chaudhuri A Tomar $R$ Dhindsa $S$ Ghanim $H$ and Dandona $P$ (2006). Low Testosterone and High C-reactive Protein Concentrations Predict Low Hematocrit in Type 2 Diabetes. Diabetes Care 29:2289-2294.

11. Dandona A Dhindsa S and Chaudhuri A(2008).Testosterone Concentration in Young Patient With Diabetes Mellitus .Sighted on www. UroToday .com.[ Abstract].

12. SAS .SAS/ STAT(2001) :User's Guide For Personal Computers. SAS International .Inc.Cary.N.C. USA.

13. Dhindsa S Prabhakar S Sethi M Bandyopadhyay A Chaudhuri A and Dandona P (2004). Frequent Occurrence of Hypogonadotropic Hypogonadism in Type 2 Diabetes. J Clin Endo Metab. 89:5462-5468. 
14. Pitteloud $N$ Mootha VK Dwyer AA Hardin $M$ Lee $H$ Eriksson KF Tripathy D Groop L Yialamas M Elahi D and Hayes F J(2000). Relationship Between Testosterone Levels, Insulin Sensitivity, and Mitochondrial Function in Men. Diabetes Care.29:1120-1123.

15. Holmang A Bjorntorp P (1992). The Effects of Testosterone on Insulin Sensitivity in Male Rats. Acta Physiol Scand 146:505-510.[Medline].

16. Bruning JC Gautam D Burks DJ Gillette J Schubert M Orban P C Klein R Krone W Muller-Wieland D and Kahn CR (2000).Role of Brain Insulin Receptor in Control of Body Weight and Reproduction. Sci 289:2122-2125.

17. Burcelin $\mathrm{R}$ Thorens $\mathrm{B}$ Glauser $\mathrm{M}$ Gaillard RC Pralong FP (2003).Gonadotropin-Releasing Hormone Secretion From Hypothalamic Neurons Stimulation by Insulin and Potentiation by Leptin. Endo. 144:44844491.

18. Adashi EY Hsueh AJW Yen SSC (1981). Insulin Enhancement of Luteinizing Hormone and Follicle-Stimulating Hormone Release by Cultured Pituitary Cells. Endo. 108:1441-1449... A Abstract].

19. Lin $\mathrm{T}$ Vinson $N$ Terracio L(1986). Characterization of Insulin and InsulinLike Growth Factor Receptors in Purified Leydig Cells and Their Role in Steroidogenesis in Primary Culture: A comparative study. Endo. 119:16411647.[ Abstract].

20. Bebakar WM Honour JW Foster D Liu Y L Jacobs H S (1990).Regulation of Testicular Function by Insulin and Transforming Growth Factor- $ß$. Steroids 55:266-269.

21. Benitez A and Perez Diaz J(1985).Effect of Streptozotocin-Diabetes and Insulin Treatment on Regulation of Leydig Cell Function in the Rat. Horm. Metab. Res. 17:5-7.[Medline]

22. Pasquali $R$ Macor $C$ Vicennati $V$ Novo $F$ De lasio $R$ Mesini $P$ Boschi $S$ Casimirri F Vettor R(1997).Effects of Acute Hyperinsulinemia on Testosterone Serum Concentrations in Adult Obese and Normal-Weight Men. Metabolism 46:526-529.[Medline]

23. Pitteloud $N$ Hardin $M$ Andrew A Valassi $E$ yialamas $M$ Elahi $D$ and Hayes FJ(2005).Increasing Insulin Resistance is Associated With a Decrease in Leydig Cell Testosterone Secretion in Men. The J Clin Endo Metab.;90(5): 2636-2641.

24. Rosner W Hyrb DJ Khan MS Nakhla AM Romas NA(1990). Androgen and Estrogen Signaling At the Cell Membrane Via G-proteins and Cyclic Adenosine Monophosphate. Steroids 64:100-106, [Medline]

25. Svartberg J Jenssen T Sundsfjord J Jorde R(2004). The Associations of Endogenous Testosterone and Sex Hormone-Binding Globulin With Glycosylated Hemoglobin Levels, in Community Dwelling Men. The Tromso Study. Diabetes Metab. 30:29-34.[Medline] .

26. Means RT Krantz SB(1992). Progress in Understanding the Pathogenesis of the Anemia of Chronic Disease. Blood 80:1639-1647.

27. Voulgari PV Kolios G Papdopoulos GK Katsaraki A Seferiadis K Dro-sos AA(1999).Role of Cytokines in the Pathogenesis of Anemia of Chronic Disease in Rheumatoid Arthritis. Clin Immunol 92: 153-160.

28. Papadaki HA Kritikos HD Gemetzi C Koutala H Marsh JC Boumpas DT Eliopoulos G D(2002).Bone Marrow Pprogenitor Cell Reserve and Function and Stromal Cell Function are Defective in Rheumatoid Arthritis; Evidence for A Tumor Necrotic Factor $\alpha$-mediated Effect.Blood 99:1610-1619. 